\title{
TÜRKİYE TURİZM SEKTÖRÜNÜN DÜNYA SEKTÖR LİDERLERİ KARŞISINDAKI REKABET GÜCÜ
}

\section{Nurdan KUŞAT*}

\section{öz}

Bu çalışmada iki amaç ve bu amaçlara ulaşmak için kullanılan iki yöntem bulunmaktadır. Amaçlardan bir tanesi; Türkiye ve en yüksek turizm geliri sahibi 5 ülkenin turizm sektöründeki karşılaştırmalı üstünlüklerini ortaya koymaktır. Diğer amaç ise; Türkiye'nin bu 5 ülke karşısındaki karşılaştırmalı ihracat performansını gözlemlemektir. İlk amaca ulaşmak için sektörel rekabet gücü ölçümlemesinde yaygın olarak kullanılan RCA (Açıklanmış Karşılaştırmalı Üstünlükler) endeksinden, ikinci amaca ulaşmak için de CEP (Karşılaştırmalı İhracat Performansı) endeksinden yararlanılmaktadır. RCA endeksi sonuçlarına göre Türkiye'nin turizm sektöründeki rekabet avantajı yüksek bulunmuştur. CEP endeksi sonuçlarına göre de Türkiye'nin sadece Tayland karşısındaki ihracat performansının düşük olduğu gözlenmektedir.

Anahtar Sözcükler: Rekabet Gücü, Karşılaştırmalı Üstünlükler, RCA Endeksi, CEP Endeksi, Turizm Sektörü

\section{COMPETITIVENES OF TURKEY TOURISM SECTOR AGAINST THE WORLD SECTOR LEADERS}

\section{ABSTRACT}

There are two purposes in this study and two methods used to achieve these purposes. One of them is that reveal the comparative advantage of Turkey and 5 countries' which have the highest tourism revenue in tourism sector. The other purpose is to observe the comparative performance of these five countries against Turkey's exports performance. The RCA (Revealed Comparative Advantage) index is used to measure sectoral competitiveness to achieve the first objective, and the CEP (Comparative Export Performance) index is used to achieve the second objective. According to the results of RCA index, Turkey's tourism sector competitive advantage was found higher. According to the CEP index results, it was observed that only Turkey's export performance was lower than Thailand.

Keywords: Competitivenes, Comparative Advantage, RCA Index, CEP Index, Tourism Industry

\footnotetext{
* Isparta Uygulamalı Bilimler Üniversitesi, Isparta Meslek Yüksekokulu, ISPARTA, E-posta: nurdankusat@isparta.edu.tr, (iD) https://orcid.org/0000-0002-2823-8948
} 


\section{GİRİş}

Turizm sektörü günümüzde hem gelişmiş hem de gelişmekte olan ülkeler için en gözde sektör olarak kendisini göstermektedir. Bu durumun ortaya çıkmasında etken rol oynayan pek çok faktör bulunmaktadır. Bu etkenlerden bir tanesi turizmin mal ticaretinden farklılı̆ıdır. Turizm sektörü çoğu zaman fiziksel bir mal ticaretini gerektirmez. Turist kendi isteğiyle yer değişikliğinde bulunur ve geldiği ülkede hizmet ağırlıklı alımda bulunur. Ülke ekonomileri için düşük maliyetle yarattığı yüksek katma değer, bu sektörü çekici kılan bir başka özelliktir. Yüksek üretim maliyetlerine ve ithal girdi kullanımına çok gereksinim duyulmaksızın sunulan hizmet, katma değerin artmasında en önemli rolü üstlenir. Bu özelliğini ise turizm arzının büyük oranda ülkelerin doğal kaynaklarından (coğrafya, kültür, iklim, ....) besleniyor olmasından elde eder. Turistik arzın çeşitliliği bu anlamda pek çok ülke ekonomisi için alternatif turizm faaliyetlerinin gelişmesinde önderlik eden güç olmaktadır. Aynı zamanda turistik arzın turistik talepten etkilenmesiyle de bu sektörde pek çok alternatif turizm türünün gelişmesi söz konusu olabilmektedir. Sektörün kapsama alanındaki bu genişleme, hem ülke döviz girdisi artışlarına vesile olurken, hem de ülke istihdamına önemli ölçüde katkı sağlamaktadır.

Bu çalışma Türkiye turizm sektörünün ülke içerisindeki rekabet gücünü ölçmenin yanı sıra, bu sektörün dünya turizm sektöründe başı çeken ülkeler karşısındaki ihracat performansını da ölçümlemeyi arzulamaktadır. Nihayetinde Türkiye gelişmekte olan bir ülkedir. Her gelişmekte olan ülkede olduğu gibi Türkiye'nin de; sermaye birikimi, genç nüfusun istihdamı ve ödemeler bilançosu açıkları konusunda önemli sıkıntıları vardır. Bu sıkıntıları bir nebze de olsa azaltabilmek adına, bir tür bacasız sanayi olan turizm sektöründen yararlanılması bir gerekliliktir. Çünkü 'turizm sektörü' düşük sermaye birikimine olan ihtiyaç ve sunduğu yüksek istihdam olanakları ile ülke ekonomileri için önemli bir çıkış noktasıdır. Fakat bu aşamada Türkiye'nin sektördeki gerçek rekabet gücünün ortaya konulması ve sektörel yönlendirmenin bu çerçevede yapılması, zaten kıt olan kaynakların etkin kullanımı adına bir zorunluluk yaratmaktadır.

Türkiye ile birlikte çalışma kapsamına alınan ülkeler, 2016 yılı itibariyle dünya turizm gelirleri pastasından en büyük payı alan beş ülkedir. Bu ülkeler bu pastadan aldıkları payların büyüklüğüne göre sırasıyla Amerika, İspanya, Tayland, Çin ve Fransa'dır.

Bu çalışma ile önce Türk turizm sektörünün rekabet gücü, sonra Türk turizm sektörünün rakip ülke turizm sektörleri karşısındaki 


\section{Nurdan KUŞAT}

karşılaştırmalı üstünlüğü ortaya konulacaktır. Bu amaçla önce dünyada ve Türkiye'de turizm sektörünün günümüzdeki durumu sayısal veriler ve çalışma örneklemi dahilinde incelenmekte, aynı zamanda sektörün rekabet gücü Dünya Ekonomik Forumu Seyahat ve Turizm Rekabet Endeksi çerçevesinde değerlendirilmektedir. Çalışmanın ilk bölümü bu anlamda bir tür literatür taraması ve mevcut verilerin değerlendirilmesinden oluşmaktadır.

Çalışmanın esas uygulama kısmını RCA (Revealed Comparative Advantage) ve CEP (Comparative Export Performance) endeksleri kullanılarak hesaplanan bölüm oluşturmaktadır. Ülke bazlı sektörel rekabet gücünün belirlenmesinde RCA endeksi ve ülkelerin sektörel ihracat performanslarının ortaya koyulmasında CEP endeksi kullanılmaktadır. RCA endeksi ile sektörün rekabet gücü hem Türkiye, hem de seçilmiş ülkeler bazında hesaplanmakta ve bu endeks ile sektör hem genel olarak, hem de iş ve kişisel amaçlı turistik faaliyetler açısından bölümlendirilerek bir değerlendirme yapılmaya çalışılmaktadır. Ayrıca kişisel turizm faaliyetleri sağlık, eğitim ve diğer turizm faaliyetleri olarak da sınıflandırııp rekabet gücü ölçümü yapılmaktadır. CEP endeksi ile de Türkiye'nin sektör lideri ülkeler karşısındaki ihracat performansı karşılaştırmalı bir şekilde hesaplanmaktadır. Bu hesaplamada turizm faaliyetleri önce bir bütün olarak, sonra kişisel faaliyetlerin amacına göre (sağlık, eğitim ve diğer) ayrı ayrı hesaplanarak değerlendirilmektedir.

\section{DÜNYADA VE TÜRKIYYE'DE TURİZM SEKTÖRÜ VE REKABET}

Bu bölümü çalışmanın örneklemini de göze alarak 2 alt bölümde incelemek daha doğru olabilir. Bu nedenle ilk kısım örneklemde yer alan ülkelerin dünya turizm sektöründeki ekonomik değerlere göre durumuna, ikinci kısım Dünya Ekonomik Forumu tarafından iki yılda bir yayımlanan Seyahat ve Turizm Rekabet Endeksi sonuçlarına odaklanmaktadır.

\section{Örneklem Çerçevesinde Turizm Sektörü Ekonomisi}

Dünya Turizm Örgütü'nün (UNWTO) resmi açıklamalarına göre 2016 yılı dünya turizm gelirleri toplamı, 2015'e göre $\% 2$ oranında artış göstererek, 1 trilyon 220 milyar \$'a ulaşmıştır. Bu gelirin yaklaşık \%17'lik kısmını tek başına ABD elde etmektedir. ABD'yi \%4,9'luk gelir payı ile İspanya, \%4,1 ile Tayland, \%3,9 ile Çin ve \%3,5 ile Fransa takip etmektedir. Bu sonuçlar 5 ülkenin dünya turizm gelirlerinin yaklaşık 3 'de 1 'ini elde ettiği anlamına gelir ki, dünyadaki ülke sayısı düşünüldüğünde bu oldukça önemli bir paydır. Türkiye ise 2016 yılı sektörel verilerine göre 
en çok turist çeken 10. ülke olmasına rağmen, dünya turizm gelirinden $\% 1,8$ oranında pay alabilmektedir. Elde edilen bu gelir miktarı ise Türkiye'yi turizm gelirlerinden en yüksek pay alan 17. ülke konumuna getirmektedir.

2012-2016 yıl aralığında dünya turizm gelirinden en yüksek payı alan beş ülke ve Türkiye'nin sektörel açıdan elde ettikleri gelirler Tablo 1 'de gösterilmektedir.

Tablo 1: Örneklem Dahilindeki Ülkelerde Turizm Gelirleri ( 20132016 / bin \$)

\begin{tabular}{lllllll} 
Yıllar & Türkiye & Amerika & İspanya & Tayland & Çin & Fransa \\
\hline 2012 & 29.007 .003 & 126.000 .000 & & & & \\
2013 & 32.308 .991 & 172.900 .000 & 62.600 .000 & 41.800 .000 & 51.700 .000 & 56.700 .000 \\
2014 & 34.305 .904 & 177.200 .000 & 65.200 .000 & 38.400 .000 & 56.900 .000 & 55.400 .000 \\
2015 & 31.464 .777 & 205.400 .000 & 56.500 .000 & 44.900 .000 & 45.000 .000 & 44.900 .000 \\
2016 & 22.107 .440 & 205.900 .000 & 60.300 .000 & 49.900 .000 & 44.400 .000 & 42.500 .000 \\
\hline
\end{tabular}
Kaynak: https://www.e-unwto.org/doi/book/10.18111/9789284419029 (erişim: 01.07.2018)

2016 yllı turizm gelirleri verilerine göre dünyada turizm sektöründen en yüksek kazancı elde eden ülkenin Amerika olduğu aşikardır (205 milyar \$). Amerika'yı sırasıyla İspanya (60,3 milyar \$), Tayland (49,9 milyar \$), Çin (44,4 milyar \$) ve Fransa (42,5 milyar \$) takip etmektedir. Türkiye ise turizm sektöründen 22,1 milyar $\$$ 'lık bir gelir elde etmektedir.

Ülkeler arasındaki turistik faaliyetlerin gerçekleştirilme gerekçeleri farklılıklar arz eder. EBOPS (Extended Balance of Payments Services Classification) sınıflandırması olarak bilinen ve Birleşmiş Milletler tarafından yayınlanan OECD ve EUROSTAT'ın ortak sınıflandırma sistemi çerçevesinde bu gerekçeler iş ve kişisel amaçlı olmak üzere iki alt başlıkta değerlendirilir. Bu sistematik ayrımdan yola çıkılarak, ülkelerin turizm sektörü ithalat ve ihracat payları, faaliyetin gerçekleştirilme gerekçeleri (i̧̧ ve kişisel) çerçevesinde oransal olarak hesaplanıp, Tablo 2 ve Tablo 3'de verilmiştir. 


\section{Nurdan KUŞAT}

Tablo 2: Örneklem Dahilindeki Ülkelerde İş Amaçlı Gerçekleştirilen Turizm Faaliyetlerinin İthalat ve İhracat Payları (\%)*

\begin{tabular}{lllllllll} 
Yıllar & \multicolumn{2}{c}{ Türkiye } & \multicolumn{2}{c}{ Amerika } & \multicolumn{2}{c}{ Tayland } & \multicolumn{2}{c}{ Fransa } \\
\hline & $\begin{array}{l}\text { İthalat } \\
\text { Payı }\end{array}$ & $\begin{array}{l}\text { İhracat } \\
\text { Payı }\end{array}$ & $\begin{array}{l}\text { İthalat } \\
\text { Payı }\end{array}$ & $\begin{array}{l}\text { İhracat } \\
\text { Payı }\end{array}$ & $\begin{array}{l}\text { İthalat } \\
\text { Payı }\end{array}$ & $\begin{array}{l}\text { İhracat } \\
\text { Payı }\end{array}$ & $\begin{array}{l}\text { İthalat } \\
\text { Payı }\end{array}$ & $\begin{array}{l}\text { İhracat } \\
\text { Payı }\end{array}$ \\
\hline 2012 & 32 & 68 & 34 & 66 & 6 & 94 & - & - \\
2013 & 12 & 88 & 30 & 70 & 7 & 93 & - & - \\
2014 & 12 & 88 & 28 & 72 & 11 & 89 & - & - \\
2015 & 40 & 60 & 27 & 73 & 10 & 90 & 73 & 27 \\
2016 & 46 & 54 & 28 & 72 & - & - & 74 & 26
\end{tabular}

Kaynak: https://comtrade.un.org/data/ (erişim: 15.07.2018)

*(Hesaplamalar tarafımdan yapılmıştır)

İş amaçlı gerçekleştirilen turistik faaliyetlerde, incelenen ülkeler için faaliyet sonuçları, Fransa hariç, sürekli ihracat ağırlıklı gerçekleşmiştir. Bu ülkeler için iş odaklı turistik süreçte gelir boyutu gider boyutunun üzerinde gelişme göstermektedir. Özellikle bu faaliyet kolunda Tayland'ın ihracat payının ithalat payına oranla yüksekliği dikkat çekmektedir. Hatta 2015 yılında iş amaçlı turizm dış ticaretinin \%90'ı inracattan oluşmaktadır ve bu durum ülkenin iş amaçlı turizmin gelir boyutundan çok yüksek oranda yararlandığını anlatmaktadır. Amerika ise iş amaçlı sektör faaliyetlerinden inracat (gelir) adına yıllar itibariyle artan oranlarda yararlanmışır (2012 yılı ihracat oranı \%66, 2016 yılı ihracat oranı \%72). Türkiye'nin ise iş amaçlı turistik faaliyetlerdeki ihracat ve ithalat payının birbirine yakın olduğu gözlenmektedir (2016 yılı için Türkiye'nin ihracat oranı $\% 54$, ithalat oranı $\% 46$ 'dır). Fakat ithalat ve inracat oranlarındaki bu yakınlığa rağmen elde edilen turizm gelirleri, turizm giderlerinin üzerinde olup, bu durum da olumlu olarak değerlendirilebilir. Oysa ki Fransa'nın iş amaçlı dış turistik faaliyetlerde ithalat payının yüksek olduğu görülmektedir (2016 yılı ithalat payı \%74). Fransa iş amaçlı turizm sürecinden gelir elde edememekte, hatta bu süreçte kayıplara uğramaktadır. 
Türkiye Turizm Sektörünün Dünya Sektör Liderleri KarşıSındaki Rekabet Gücü

Tablo 3: Örneklem Dahilindeki Ülkelerde Kişisel Amaçlı Gerçekleştirilen Turizm Faaliyetlerinin İthalat ve İhracat Payları (\%)*

\begin{tabular}{lllllllll} 
Yıllar & \multicolumn{2}{c}{ Türkiye } & \multicolumn{2}{c}{ Amerika } & \multicolumn{2}{c}{ Tayland } & \multicolumn{2}{c}{ Fransa } \\
\hline & $\begin{array}{l}\text { İthalat } \\
\text { Payı }\end{array}$ & $\begin{array}{l}\text { İhracat } \\
\text { Payı }\end{array}$ & $\begin{array}{l}\text { İthalat } \\
\text { Payı }\end{array}$ & $\begin{array}{l}\text { İhracat } \\
\text { Payı }\end{array}$ & $\begin{array}{l}\text { İthalat } \\
\text { Payı }\end{array}$ & $\begin{array}{l}\text { İhracat } \\
\text { Payı }\end{array}$ & $\begin{array}{l}\text { İthalat } \\
\text { Payı }\end{array}$ & $\begin{array}{l}\text { İhracat } \\
\text { Payı }\end{array}$ \\
\hline 2012 & 10 & 90 & 40 & 60 & 17 & 83 & - & - \\
2013 & 15 & 85 & 37 & 63 & 14 & 86 & - & - \\
2014 & 16 & 84 & 37 & 63 & 16 & 84 & - & - \\
2015 & 12 & 88 & 38 & 62 & 15 & 85 & 38 & 62 \\
2016 & 15 & 85 & 40 & 60 & -- & - & 41 & 59 \\
\hline
\end{tabular}

Kaynak: https://comtrade.un.org/data/ (erişim: 15.07.2018)

*(Hesaplamalar tarafımdan yapılmıştır)

Kişisel amaçlı gerçekleştirilen turizm faaliyetlerinde de incelenen ülkeler için inracat ve ithalat arasındaki oransal dağılım, iş amaçı gerçekleştirilen turizm faaliyetlerindeki sonuçlardan farklılık göstermektedir. Tayland, kişisel amaçlı turistik faaliyetlerde yine yüksek oranda turist çeken yapısıyla dikkat çekerken (2015 yılı ihracat payı \%85), Türkiye'nin de kişisel amaçlı turistik faaliyetlerde yüksek oranda ihracat payına sahip olduğu görülmektedir (2015 yılı ihracat payı \%85). Amerika'nın ise ihracat payının iş amaçlı turistik faaliyetlerde olduğu kadar yüksek olmadığı (2016 yılı için \%60) gözlenmektedir. Fransa'nın kişisel amaçı turistik faaliyetlerdeki inracat payı ise ithalat payının üzerindedir (2016 yılı ihracat payı \%59).

Her iki tablonun sonuçları, gerek iş, gerekse kişisel amaçlı gerçekleştirilen turizm faaliyetlerinden ödemeler dengesi adına en çok faydayı Tayland'ın elde ettiğini göstermektedir.

\section{Seyahat ve Turizm Rekabet Endeksi ve Örneklem Dahilindeki Ülkeler}

Seyahat ve Turizm Rekabet Endeksi; Dünya Ekonomik Forumu tarafından, farklı ülkelerdeki seyahat ve turizm sektörünü geliştirmeyi cazip hale getiren faktörleri ve politikaları ölçmeyi hedefleyen ve bu amaç çerçevesinde ülkelerin seyahat ve turizm ortamlarının ayrıntılı şekilde değerlendirilmesini sağlayan uluslararası bir endekstir (http://www.tuik.gov.tr/UstMenu.do?metod=istendeks). Bu endeksin kapsamına giren ve endeksin hesaplanmasında kullanılan ölçeklendirme kategorileri Tablo 4'de verilmektedir. 


\section{Nurdan KUŞAT}

Tablo 4: Seyahat ve Turizm Rekabet Endeksi Alt Endeksleri ve Kapsamı

\begin{tabular}{|c|c|c|c|}
\hline $\begin{array}{c}\text { A. Çevreyi } \\
\text { Etkinleştirmek Alt } \\
\text { Endeksi }\end{array}$ & $\begin{array}{c}\text { B. Seyahat ve } \\
\text { Turizm Politikası ve } \\
\text { Etkinleştirilmesi Alt } \\
\text { Endeksi }\end{array}$ & $\begin{array}{l}\text { C. Altyapı Alt } \\
\text { Endeksi }\end{array}$ & $\begin{array}{c}\text { D. Doğal ve Kültürel } \\
\text { Kaynaklar Alt Yapısı } \\
\text { Endeksi }\end{array}$ \\
\hline $\begin{array}{l}\text {. İş çevresi, } \\
\text {. Emniyet ve } \\
\text { güvenlik } \\
\text {. Sağlık ve hijyen } \\
\text {. İnsan kaynakları } \\
\text { ve işgücü piyasası } \\
\text {. Bilgi iletişim } \\
\text { teknolojileri }\end{array}$ & $\begin{array}{l}\text { Seyahat ve turizme } \\
\text { öncelik tanıma } \\
\text {. Uluslararası açılık } \\
\text {. Fiyat rekabeti } \\
\text {. Çevresel } \\
\text { sürdürülebilirlik }\end{array}$ & $\begin{array}{l}\text {. Havayolu ulaşımı } \\
\text { altyapısı } \\
\text {. Kara ve liman } \\
\text { ulaşımı altyapısı } \\
\text {. Turist hizmetleri } \\
\text { altyapısı }\end{array}$ & $\begin{array}{l}\text {. Doğal kaynaklar ve } \\
\text { kültürel kaynaklar } \\
\text {. İş seyahatleri }\end{array}$ \\
\hline
\end{tabular}

Kaynak: http://www.tuik.gov.tr/UstMenu.do?metod=istendeks (erişim 01.07.2018)

Tablo 4'den de anlaşılacağı üzere Seyahat ve Turizm Rekabet Endeksi dört alt endeksten teşekkül etmektedir: (1) Çevreyi etkinleştirmek, (2) seyahat ve turizm politikası ve etkinleştirilmesi, (3) altyapı ve (4) doğal ve kültürel kaynaklar altyapısı başıklarında tanımlanan bu alt endekslerin her biri de kendi içinde uygun tanımlamalardan elde edilen toplam 14 kriterden oluşmaktadır. Hesaplama ise Dünya Ekonomik Forumu'nun Yönetici Görüş Anketi sonuçlarından ve diğer kaynaklardan elde edilen nicel veriler temel alınarak gerçekleştirilmektedir.

Günümüzde son Seyahat ve Turizm Rekabet Endeksi 2017 yılında yayımlanmıştır. Bu endekste 136 ülke yer almaktadır. 2017 ylı Seyahat ve Turizm Rekabet Endeksi'ne göre sıralamanın başında yer alan ilk 10 ülke ve endeks puanları Tablo 5'de verilmektedir.

Tablo 5: Seyahat ve Turizm Rekabet Endeksi Sıralamasında İlk 10 Ülke (2017)

\begin{tabular}{lllllll} 
Ülke & Sıra & Puan & Ülke & Sıra & Puan \\
\hline İspanya & 1 & 5,43 & Amerika & Birleşik & 6 & 5,12 \\
Fransa & 2 & 5,32 & Avustralya & 7 & 5,10 \\
Almanya & 3 & 5,28 & İtalya & 8 & 4,99 \\
Japonya & 4 & 5,26 & Kanada & 9 & 4,97 \\
Birleşik Krallık & 5 & 5,20 & İsviçre & 10 & 4,94 \\
\hline
\end{tabular}

Kaynak: http://www.tuik.gov.tr/UstMenu.do?metod=istendeks (erişim 01.07.2018)

2017 yılı Seyahat ve Turizm Rekabet Endeksi'nde yer alan ilk 10 ülkeye bakıldığında, dünya turizm gelirinden en yüksek payı alan 5 ülkeden 3 tanesinin bu sıralamada yer aldığı görülürken (İspanya 1., Fransa 2. ve Amerika 6.), 2 tanesinin bu sıralamada olmadığı (Çin ve Tayland) dikkat çekmektedir. Çin 3,99 puanla 39., Tayland ise 3,44 
puanla 34. sırada yer almaktadır. Türkiye ise 4,44 puanla 44 . sırada yer almıştır.

Dünya turizm gelirinden en yüksek geliri elde eden ve Seyahat ve Turizm Rekabet Endeksi sıralamasında ilk 10 ülke arasına giren Amerika, İspanya ve Fransa'nın yanı sıra; gelir sıralamasında derece yapıp Endeks sıralamasında geriye düşen Çin ve Tayland'ın durumu çok da şaşırıı değildir. Çünkü ilk 3 ülke gelişmişlik düzeyi yüksek olan ülkelerken, son 2 ülke gelişmekte olan ülke statüsündedir. Türkiye'de bu 2 ülkeyle aynı kaderi paylaşmaktadır.

Diyebiliriz ki ülkenin gelişmişlik düzeyine bakılmaksızın, bazı sektörlerde yüksek gelir elde edilebilmesi mümkündür. ${ }^{1} \mathrm{Bu}$ süreci Türkiye'nin de kendi lehine döndürebilmesi adına yapabilecekleri mutlaka vardır. Ama diğer açıdan önemli olan gerek turizm sektöründen gerekse diğer sektörlerden elde edilen gelirleri sürdürülebilir kılmaktır. Bunun için de sektörel rekabet gücünün yüksek olmasına ve sektördeki rekabet avantajının iyi değerlendirilmesine ihtiyaç vardır. Küreselleşmenin ülkeler için bir yandan yeni ticari fırsatlar yaratırken, diğer yandan zorlu bir rekabet ortamı oluşturarak, rekabet gücü zayıf ülkeler için bir tehdit unsuru ortaya çıkardığı (Yeşilkaya, 2017:70) hatıllanacak olursa; bir ekonomide sektörler adına hem sürdürülebilirliğin hem de rekabet gücünün eş anlı sağlanması gerektiği daha iyi anlaşılacaktır.

\section{LITTERATÜR TARAMASI}

'Karşılaştırmalı Üstünlükler' uluslararası ticaretin en önemli varsayımlarından bir tanesi olup, Klasik ekolle hayat bulan ve günümüzde uluslararası ticaretin hangi şartlarda ülke ekonomilerine fayda sağlayacağını açıklamada yaygın olarak kullanılmaya devam eden bir olgudur. Öyle ki Lin vd. (1999) bir adım daha ileri giderek, bir ülke için karşılaştırmalı üstünlüklerin kaynağı ne olursa olsun, bu olgunun, ülke dış ticaretinin maksimum noktaya taşınabilmesinde en iyi strateji olduğuna vurgu yapmaktadırlar. Gerek ülkelerin rekabet gücünün ortaya konması, gerek karşılaştırmalı üstünlüğe sahip olunan sektörleri tespit etmek ülkeler için önem arz eder. Bu nedenledir ki günümüzde olduğu gibi geçmişte de; ülke, sektör ve firma bazı karşılaştırmalı üstünlüklerin hesaplanması adına geliştirilmiş endekslere sıklıkla rastlanmaktadır.

\footnotetext{
${ }^{1}$ Bu sonuca ulaşılmasında, tablo 4'de yer alan ve Seyahat ve Turizm Rekabet Endeksi'nin hesaplanmasında kullanılan kriterlerin, ülkelerin gelişmişlik düzeyiyle yakından ilişkili olması önem arz etmektedir.
} 


\section{Nurdan KUŞAT}

Çünkü yeni ekonomik düzenin en önemli getirisi olan rekabet önemli, ama rekabet gücü daha da önemlidir. T.C. Kalkınma Bakanlığı tarafından hazırlanan 'Türkiye Sürdürülebilir Kalkınma Raporu - Geleceği Sahiplenmek (2012)' başlıklı raporda; hem sürdürülebilir kalkınma için ekonominin rekabet gücünün artırımasının gerekliliği ısrarla vurgulanmakta, hem de Türk turizm sektörünün rekabetçi özelliklerine dikkat çekilmektedir.

Uluslararası ticaret literatüründe bir ülkenin rekabet gücünü ölçmeye yönelik ilk çalışmaların Liesner tarafından 1958 yılında yapılmış olduğu görülmektedir (Utkulu ve Seymen, 2004:7-8). Fakat bu konuda öne çıkan en ünlü endeks Açıklanmış Karşılaştırmalı Üstünlükler (Revealed Comparative Advantage - RCA) adıyla bilinen Balassa'ya ait rekabet endeksidir (Bilas ve Bošnjak, 2015). Balassa bu endeksi Liesner'in endeksinden yararlanmak kaydıyla geliştirmiş ve zamanla Balassa endeksi olarak da adlandırılan bu endeks sayesinde yeni endeksler geliştirilmeye devam etmiştir.

Balassa Endeksinden uyarlanan ve bir ülkenin rakip ülkeler karşısındaki sektörel rekabet gücünü ölçmek amacıyla kullanılan bir diğer ünlü endeks de Donges vd.'ne (1982) ait olan ve Karşılaştırmalı İhracat Performansı Endeksi (Comparative Export Performance - CEP) olarak bilinen endekstir.

Donges vd. (1982) bu endeksi RCA endekslerinin olası yanlış değerlendirmelerine bir alternatif olarak geliştirmişlerdir. Çünkü RCA endeksleri ithalatı da içine almakta, bir ülkenin ithalatı ise ithalat üzerindeki politik kararları da (tarife ve kotalar gibi) içinde barındırdığından, yanlış değerlendirmelere sebep olabilmektedir. Oysaki Donges vd.' ne göre (1982:83), bir ülkenin dış ticaretinde; ihracat üzerindeki teşviklerin ithalat üzerindeki politik uygulamalardan daha az önemli olması, rekabet ölçümlemesinde inracat verilerinden yararlanılmasını daha doğru kılacaktır.

Fakat literatüre bakıldığında yakın geçmişte de hem RCA, hem CEP endeksi kullanılarak gerçekleştirilmiş, farklı ülke ve farklı sektörleri içerisine alan pek çok çalışmaya rastlanmaktadır. Yerli ve yabancı araştırmacılara ait bu çalışmalardan bazılarına Tablo 6 ve 7'de yer verilmektedir. 
Türkiye Turizm Sektörünün Dünya Sektör Liderleri Karşısındaki Rekabet Gücü

Tablo 6: RCA Endeksine Göre Yapılmış Olan Bazı Araştırmalar

\begin{tabular}{|c|c|c|c|}
\hline Araştırmacı & Yוl & Karşılaştırma yapılan ülkeler & İncelenen sektör \\
\hline $\begin{array}{l}\text { Kaitila } \\
\text { Widgren }\end{array}$ & 1999 & Baltık ülkeleri - AB & Genel \\
\hline $\begin{array}{l}\text { Ferto } \\
\text { Hubbard }\end{array}$ & 2002 & Macaristan - AB & Genel \\
\hline Altay ve Gacaner & 2003 & Türkiye - Çin & Tekstil ve Hazır Giyim \\
\hline Hatırlı vd. & 2003 & Türkiye - AB & Tekstil ve Hazır Giyim \\
\hline Çoban ve Kök & 2005 & Türkiye - AB & Tekstil \\
\hline Hossain & 2006 & Bangladeş & Su Ürünleri \\
\hline Seyoum & 2007 & Genel & Hizmet \\
\hline Serin ve Civan & 2008 & Türkiye - AB & $\begin{array}{l}\text { Domates, Zeytinyağı ve } \\
\text { Meyve Suyu }\end{array}$ \\
\hline $\begin{array}{l}\text { Jayawickrama ve } \\
\text { Thangavelu }\end{array}$ & 2008 & Singapur-Çin-Hindistan & Endüstri \\
\hline Yücel & 2010 & Türkiye - Çin & Tekstil ve Hazır Giyim \\
\hline Amighini vd. & 2011 & İtalya & Genel \\
\hline Kara ve Erkan & 2011 & Türkiye & Emek Yoğun \\
\hline Erlat ve Erlat & 2012 & Türkiye - 12 Ortadoğu Ülkesi & Genel \\
\hline Riaz ve Jansen & 2012 & Pakistan & Tarım \\
\hline Barattieri & 2014 & ABD - Japonya - Almanya - Çin & Hizmet \\
\hline Mahajan vd. & 2015 & Hindistan - İrlanda - İsrail & İlaç \\
\hline
\end{tabular}

Tablo 7: CEP Endeksine Göre Yapılmış Olan Bazı Araştırmalar

\begin{tabular}{lcll}
\hline $\begin{array}{l}\text { Saraçoğlu ve } \\
\text { Köse }\end{array}$ & 2000 & $\begin{array}{l}\text { İtalya, Fransa, Belçika, ABD, } \\
\text { Tayland, Almanya, İspanya, } \\
\text { Kanada, Hollanda, Belçika, } \\
\text { Lüksemburg, İngiltere, } \\
\text { Danimarka, Çin ve Japonya }\end{array}$ & $\begin{array}{l}\text { Makarna, Bisküvi ve } \\
\text { Buğday Unu }\end{array}$ \\
\hline $\begin{array}{l}\text { Akgüngör, } \\
\begin{array}{l}\text { Barbaros ve } \\
\text { Kumral }\end{array}\end{array}$ & 2002 & $\begin{array}{l}\text { Türkiye, Yunanistan, Portekiz, } \\
\text { İspanya }\end{array}$ & $\begin{array}{l}\text { Domates, Üzüm ve } \\
\text { Narenciye İşleme }\end{array}$ \\
\hline $\begin{array}{l}\text { Kösekahyaoğlu } \\
\text { ve Özdamar }\end{array}$ & 2005 & $\begin{array}{l}\text { Türkiye, Çek, Macaristan, } \\
\text { Polonya, Estonya }\end{array}$ & Tüm Mal Grupları \\
\hline $\begin{array}{l}\text { Türkekul, } \\
\text { Günden, Abay ve } \\
\text { Miran }\end{array}$ & 2010 & $\begin{array}{l}\text { Türkiye, Tunus, İspanya, } \\
\text { Yunanistan, Suriye }\end{array}$ & Zeytinyağı \\
\hline Gacaner Atış & 2014 & $\begin{array}{l}\text { Türkiye, AB-27, ABD, Orta } \\
\text { Doğu-Kuzey Afrika }\end{array}$ & Tekstil ve Konfeksiyon \\
\hline Şahin & 2016 & Türkiye, BRIC & İmalat \\
\hline $\begin{array}{l}\text { Alidou, Ceylan ve } \\
\text { Ilbasmıs, }\end{array}$ & 2017 & Benin, Nijerya, Burkina Faso & Tarım \\
\hline
\end{tabular}

Farklı yıllarda ve farklı ülkeler üzerinde yapılan bu çalışmaların ortak özelliğinin mal ticareti üzerinde gerçekleştirilmiş çalışmalar olması dikkat çekmektedir. Literatür taraması sırasında turizm sektöründe 


\section{Nurdan KUŞAT}

yapılmış olan benzer bir çalışmaya rastlanmamıştır. Fakat hizmet sektörünü baz alan tek bir çalışmaya rastlanmıştır².

\section{ÇALIŞMANIN YÖNTEM, BULGU VE SONUÇLARI}

\section{Yöntem}

Çalışmada Türkiye'nin turizm sektöründeki rekabet gücünü ölçmek için 2 farkı endeksten birlikte yararlanılması planlanmışır. Bu endekslerden bir tanesi RCA (Revealed Comperative Advantage) Açıklanmış Karşılaştırmalı Üstünlükler Endeksi, diğeri CEP (Comperative Export Performance) Karşılaştırmalı İhracat Performansı Endeksidir.

Balassa (1965) tarafından rekabet gücünün ölçülmesinde kullanılmak amacıyla geliştirilen RCA endeksi, bu amaçla yaygın şekilde kullanılan endeks olarak dikkat çeker. Bu endeks, rekabet gücünün ölçülmesi amacıyla Balassa sonrasında da farklılaştıılarak kullanılmaya devam etmiştir. Fakat bazı uygulamacılar Balassa'nın orijinal endeksinin diğer rekabet gücü ölçümünde kullanılan endekslere göre daha az sınırlama getirdiğini vurgulamaktadırlar (De Benedictis ve Tamberi, 2002).

Rekabet gücü ölçümünde kullanmak ve RCA endekslerinin eksikliklerini gidermek amacıyla Balassa'nın endeks formülünden yola çıkılarak geliştirilmiş olan ihracat performans endekslerine de literatürde rastlanmaktadır. Donges vd. (1982) tarafından geliştirilen CEP de bu endekslerden bir tanesidir.

Çalışmada kullanılan bu endekslerin formülleri aşağıda Formül 1 ve Formül 2 olarak gösterilmiş ve sonuçların nasıl yorumlanması gerektiği açıklanmıştır.

Formül 1 (Balassa, 1965):

RCAij = (Xij /Xit) / (Mij / Mit)

Formül 1 'de;

RCAij i ülkesinin $\mathrm{j}$ mal grubundaki açıklanmış karşılaştırmalı üstünlük katsayısını; (Xij) i ülkesinin j mal grubundaki ihracatını; (Xit) i ülkesinin toplam ihracatını; (Mij) i ülkesinin j mal grubundaki ithalatını; (Mit) i ülkesinin toplam ithalatını göstermektedir. RCAij $>1$ ise i ülkesinin $\mathrm{j}$ mal grubunda rekabet gücü yüksek, RCAij $<1$ ise $\mathrm{i}$ ülkesinin $\mathrm{j}$ mal grubunda rekabet gücü düşük, RCAij $=1$ ise i ülkesinin $\mathrm{j}$ mal grubunda

2 Bu çalışma 2014 yılında A. Barattieri tarafından yapılmış olan bir çalışmadır. (Comparative advantage, service trade, and global imbalances. Journal of International Economics. 92:1-13.) 
rekabet gücü dünya uzmanlaşma düzeyiyle aynı şeklinde yorum yapılır (Coxhead, 2007).

Formül 2 (Donges vd., 1982):

CEPirj $=\left(X_{i j} / X r j\right) /\left(\sum i t / \sum r t\right)$

Formül 2'de;

CEPirj i ülkesinin rakip ülke karşısında $j$ mal grubundaki karşılaştırmalı ihracat performansı katsayısını; (Xij) i ülkesinin j mal grubundaki ihracatını; (Xrj) rakip ülkenin j mal grubundaki ihracatını; ( $\Sigma$ it) i ülkesinin toplam ihracatını; ( $\sum \mathrm{rt}$ ) rakip ülkenin toplam ihracatını göstermektedir. CEPirj>1 ise i ülkesinin $\mathrm{j}$ mal grubunda ihracatta avantaja sahip olduğu, RCAij<1 ise $\mathrm{i}$ ülkesinin $\mathrm{j}$ mal grubunda ihracatta dezavantajlı olduğu şeklinde yorum yapılır (Kösekahyaoğlu, 2012).

Hinloopen ve Van Marrewijk (2001) ise CEP endeks hesaplaması sonrası elde edilen değerlerin yorumlanmasında karşılaştırmalı üstünlüklere göre bir değerlendirilme yapılmasını uygun görmektedir. Bu araştırmacılara göre; $0<$ CEP $\leq 1$ ise karşılaştırmalı üstünlük yoktur, $1<$ CEP $\leq 2$ ise zayıf bir karşılaştırmalı üstünlük vardır, $2<$ CEP $\leq 4$ ise orta derecede karşılaştırmalı üstünlük vardır, $4<$ CEP ise güçlü bir karşılaştırmalı üstünlük vardır.

Çalışmada Birleşmiş Milletler tarafından yayınlanan ve OECD ve EUROSTAT'ın ortak sınıflandırması olan EBOPS (Extended Balance of Payments Services Classification) sınıflandırmasına göre elde edilen ticari istatistiklerden yararlanılmaktadır. $\quad \mathrm{Bu}$ bilgilere https://comtrade.un.org/data adresinden ulaşılmış, her bir ülkenin verileri bu adresten Tablo 8'de belirtilen kodlar çerçevesinde elde edilmiştir.

Tablo 8: Birleşmiş Milletlere Ait İstatistiki Sınıflandırma ve Kodları 200 TOPLAM HİZMET TICARETI

236 Turizm Ticareti

237 İş Seyahati Ticareti

240 Kişisel Seyahat Ticareti

241 Sağlıkla İlgili Seyahat Harcamaları

242 Eğitimle İlgili Seyahat Harcamaları

243 Diğer Kişisel Seyahat Harcamaları

Sınıflandırmadan da anlaşılacağı üzere; bir ülkenin turizm ticareti o ülkenin toplam hizmet ticaretinin bir parçasıdır. Ayrıca turizm ticareti; iş ve kişisel seyahat ticareti olarak bölümlenmiş ve kişisel seyahat ticareti de sağlık, eğitim ve diğer kategorilerinde özelleştirilmiştir. Çalışmanın uygulama kısmında bu başlıklardan elde edilen veriler kullanılmaktadır. 


\section{Nurdan KUŞAT}

Çalışmada 2012-2016 yıl aralığı incelenmektedir. 2012 öncesinin kapsam dışında bırakılmasında incelenen ülkelere ait ayrıntıı dış ticaret verilerine ulaşmakta yaşanan sorunlar yatmaktadır. Ayrıca bazı hesaplamalarda tüm ülkelerin ayrıntılı verileri bulunamadığı için bu alanlar boş bırakılmak zorunda kalınmıştır.

\section{Bulgular}

RCA - Açıklanmış Karşılaştırmalı Üstünlükler Endeksi Sonuçları

Türkiye ve dünya toplam turizm gelirinden en yüksek payı alan 5 ülkenin turizm sektöründeki açıklanmış karşılaştırmalı üstünlük değerleri RCA endeksi yardımıyla hesaplanmıştır. Bu hesaplamada ülkelerin toplam hizmet ticareti ve bu hizmet ticareti içerisinde yer alan turizm faaliyetine ait değerler kullanılmıştır. (200 ve 236 kodlu değerler kullanılarak hesaplama yapılmıştır). Elde edilen sonuçlar Tablo 9'da verilmektedir.

\section{Tablo 9: Ülkelere Göre Turizm Sektörü RCA Endeksi Değerleri}

\begin{tabular}{cllllll} 
YIllar & $\begin{array}{l}\text { RCA } \\
\text { Türkiye }\end{array}$ & $\begin{array}{l}\text { RCA } \\
\text { Amerika }\end{array}$ & $\begin{array}{l}\text { RCA } \\
\text { İspanya }\end{array}$ & $\begin{array}{l}\text { RCA } \\
\text { Tayland }\end{array}$ & $\begin{array}{l}\text { RCA } \\
\text { Çin }\end{array}$ & $\begin{array}{l}\text { RCA } \\
\text { Fransa }\end{array}$ \\
\hline 2012 & 2,99 & 1,12 & 1,98 & 5,79 & 0,72 & 1,19 \\
2013 & 2,93 & 1,20 & 1,90 & 6,04 & 0,72 & 1,23 \\
2014 & 2,79 & 1,19 & 1,89 & 5,23 & 0,63 & 1,12 \\
2015 & 2,36 & 1,18 & 1,96 & 4,89 & 0,70 & 1,12 \\
2016 & 2,27 & 1,14 & 1,94 & 3,45 & 0,42 & 1,08 \\
\hline
\end{tabular}

Tablo sonuçları incelenen 5 yılda da Çin hariç $(R C A<1)$ örnekleme dahil edilen tüm ülkelerin turizm sektöründeki rekabet avantajını teyit eder niteliktedir. Elde edilen sonuçlar ayrıntılı olarak incelendiğinde ise; sektörde en yüksek rekabet avantajına sahip olan ülkenin Tayland olduğu (RCA 2016 3,45) ve bu ülkeyi Türkiye'nin (RCA 2016 2,27) takip ettiği gözlenmektedir. Çin'in sektörel açıdan yüksek gelir elde etmesine rağmen, bu sektörde rekabet avantajı yakalayamamış olması, aslında çok da beklenmedik bir durum sayılmaz. Çünkü bu ülke için turizm sektörü her ne kadar yüksek döviz girdisi sağlayan bir sektör olsa da, Çin; hizmet ticaretinden ziyade ağırlıkı olarak tüm dünyaya gerçekleştirdiği yüksek mal ticareti ile dikkat çeken bir ülkedir. Bu sürecin gelişmesinde; Çin'in mevcut nüfus yapısının yanında, artan teknoloji düzeyi ve ekonomisine yoğun olarak çekmeyi başardığı doğrudan yabancı sermaye önem arz eder (Yeşilkaya, 2017:71). Dünya Ticaret Örgütü resmi internet sitesi verileri de Çin'in, AB-28'den sonra, dünyadaki en büyük ihracatçı ülke konumunun yanı sıra, ihracatındaki sanayi ağırıklı yapıyı da teyit etmektedir (www. wto.org). 
Dünya turizm gelirinden yüksek paylar alan bu ülkelerin yıllar itibariyle karşılaştırmalı üstünlüklerindeki değişimlerine de ayrıca baktığımızda ise, sektörel avantajını 2012-2016 tarih aralığında artırabilmiş tek ülkenin Amerika olduğu dikkat çekmektedir (RCA 2012 1,12 - RCA 2106 1,14). Diğer ülkelerin hepsinin rekabet avantajlarında yıllar itibariyle kayıplar olduğu gözlenmekle birlikte, en büyük avantaj kaybını Tayland'ın (RCA 2012 5,79 - RCA 2106 3,45)33 yaşamış olduğu da söylenebilir. Fakat Tayland açısından yaşanan bu olumsuzluk, Tayland'ın dünya turizm sektöründeki en yüksek rekabet avantajına sahip ülke konumunu kaybetmesine sebep olmamıştır.

Sonuçları Türkiye açısından değerlendirdiğimizde de; 2012 RCA değeri 2,99'ken, 2016'da bu değerin yaklaşık \%75'lik bir kayıpla 2,27'ye gerilediği görülmektedir. Rakamsal olarak küçük olan bu azalmanın aslında oransal olarak yüksek olduğu, hatta bu kaybın Tayland'ın yaşadığı avantaj kaybından daha da fazla olduğu dikkat çekmektedir. Bu sonuç Türkiye turizm sektör gelirlerinde önemli bir daralma yaşandığının göstergesi olarak değerlendirilebilir. Fakat ülke adına olumsuz olarak değerlendirilebilecek bu gelişmeye rağmen, Türkiye, turizm sektöründe, Tayland'dan sonra en yüksek rekabet avantajına sahip olan ülke olma özelliğini hala korumaktadır.

Turistik faaliyetlerin gerçekleştirilme amaçlarının önemi düşünüldüğünde; iş amaçlı ve kişisel amaçı turistik faaliyetlerde de ülkelerin rekabet avantajlarını değerlendirmek gerekir. Bu amaçla; Tablo 10 iş amaçlı, Tablo 11 kişisel amaçlı turistik faaliyetlerde ülke rekabet avantajlarını gözlemlemek için düzenlenmiştir. Fakat Çin'e ait iş ve kişisel amaçlı turistik faaliyetlerin ithalat ve inracat kapsamındaki yıllık değerlerine ulaşılamadığı için, Çin ile ilgili hesaplamalara bu tablolarda yer verilememiştir.

Tablo 10: İş Amaçlı Gerçekleştirilen Turizm Faaliyetlerinin RCA Endeksi Değerleri

\begin{tabular}{lllll} 
Yıllar & Türkiye & Amerika & Tayland & Fransa \\
\hline 2012 & 0,35 & 1,22 & 2,88 & - \\
2013 & 1,21 & 1,26 & 2,08 & - \\
2014 & 1,29 & 1,39 & 1,50 & - \\
2015 & 0,30 & 1,49 & 1,48 & 0,33 \\
2016 & 0,30 & 1,55 & - & 0,33 \\
\hline
\end{tabular}

3 Tayland’ın 2012-2016 yıl aralığı sektörel rekabet avantajı kaybı yaklaşık \%60'dır. 


\section{Nurdan KUŞAT}

İş amaçlı turistik faaliyetlerde Amerika ve Tayland'ın rekabet avantajı dikkat çekmektedir. Yıllar itibariyle bu sürece bakıldığında; Amerikanın rekabet avantajı 2012'den 2016'ya artarken (1,22'den 1,55'e), Tayland'ın rekabet avantajının azaldığı da (2,88'den $2015^{\prime}$ de $\left.1,48^{\prime} \mathrm{e}\right)$ gözlenmektedir. Gerek Türkiye, gerekse Fransa'nın iş amaçlı turistik faaliyetler konusunda bir rekabet avantajına sahip olmadığı görülmektedir. Ayrıca Türkiye için 2013 ve 2014 yıllarında yakalanmış olan bir rekabet avantajının bu yıllardan sonra sürdürülemediği de dikkat çekmektedir.

Tablo 11: Kişisel Amaçlı Gerçekleştirilen Turizm Faaliyetlerinin RCA Endeksi Değerleri

\begin{tabular}{lllll} 
Yıllar & Türkiye & Amerika & Tayland & Fransa \\
\hline 2012 & 1,39 & 0,95 & 0,92 & - \\
2013 & 0,94 & 0,93 & 0,94 & - \\
2014 & 0,93 & 0,92 & 0,97 & - \\
2015 & 1,44 & 0,92 & 0,97 & 1,40 \\
2016 & 1,44 & 0,92 & - & 1,35 \\
\hline
\end{tabular}

Kişisel amaçlı turistik faaliyetlerde rekabet avantajı gösteren ülkeler ise Türkiye ve Fransa'dır. Amerika ve Tayland'ın bu faaliyet alanında rekabet avantajı yakalayamadığı, hesaplanan RCA değerlerinin 1'in altında kalmasından anlaşılmaktadır.

Tablo 8 ve 9'u beraber yorumladığımızda, iş amaçlı turistik faaliyetlerde Amerika ve Tayland'ın, kişisel amaçlı turistik faaliyetlerde Türkiye ve Fransa'nın rekabet üstünlüğüne sahip ülkeler olduğu söylenebilir.

EBOPS sınıflandırma sistemi kişisel amaçla gerçekleştirilen turistik faaliyetleri; sağlık, eğitim ve diğer turistik faaliyetler kapsamında ayrı başıklar altında değerlendirmektedir. Fakat çalışma kapsamına alınan tüm ülkeler için mevcut verilerin tamamına ulaşılamadığından, her bir alanda ulaşılabilen verilerle, bu faaliyet alanlarındaki RCA endeksleri hesaplanmaya çalışılmışıı. Sağlık alanındaki kişisel amaçlı turistik faaliyetlere ait hesaplama sonuçları Tablo 12 'de, eğitim alanındaki sonuçlar Tablo 13 'de ve diğer alandaki sonuçlar da Tablo 14 'de değerlendirilmektedir. 
Tablo 12: Sağlık Turizmi RCA Endeksi Değerleri

\begin{tabular}{llll} 
Yıllar & Türkiye & Amerika \\
\hline 2012 & 0,25 & - \\
2013 & - & 1,51 & \\
2014 & - & 1,26 & \\
2015 & 5,34 & 1,17 & \\
2016 & 5,34 & 1,11 & \\
\hline \multicolumn{2}{rl}{ Sadece } & Türkiye & ve Amerika'ya ait verilerin elde edilmesiyle
\end{tabular}
hazırlanan tablo sonuçları; her iki ülkenin de rekabet gücünün yüksek olduğunu göstermekle birlikte, Türkiye'nin Amerika'ya göre daha fazla olan rekabet avantajını da ortaya koymaktadır (2016 yılı RCA değeri Türkiye'de 5,34, Amerika'da 1,11 olarak hesaplanmıştır). Bu sonuç Türkiye'nin hem dünya genelinde, hem de Amerika karşısındaki sağılı turizmi avantajını göstermektedir. Dünya geneli için bu yorumun yapılma gerekçesi ise, Amerika'nın dünya turizminden en yüksek geliri elde eden ülke olması ve Türkiye'nin de bu ülke karşısında elde ettiği yüksek rekabet avantajı olmaktadır. Aslında Türkiye'ye sadece sağlık için gelen turistlerin varlığının biliniyor olması, hatta bu geliş gidişlerin günübirlik dahi gerçekleştiğinin farkındalığı; elde edilen sonucu teyit eder niteliktedir. Nihayetinde Türkiye çoğu ülke vatandaşı için sağlık turizminin cazibe merkezidir. Edinsel ve Adıgüzel de (2014:180) Türkiye'nin sağlık turizmi SWOT analizini gerçekleştirdikleri çalışmalarında Türkiye'nin sağlık turizmindeki güçlü yönlerini ve fırsatlarını ortaya koyarken, Türkiye'ye sağlık amaçlı gelen turist sayısının istikrarlı bir şekilde arttığına değinmektedirler.

Tablo 13: Eğitim Turizmi RCA Endeksi Değerleri

\begin{tabular}{llll} 
YIllar & Türkiye & Amerika & Tayland \\
\hline 2012 & 0,08 & 2,69 & 0,02 \\
2013 & - & 2,49 & 0,01 \\
2014 & - & 2,64 & 0,02 \\
2015 & 0,09 & 2,97 & 0,01 \\
2016 & 0,09 & 3,39 & - \\
\hline \multicolumn{2}{r}{ Türkiye, Amerika ve Tayland'a ait verilere ulaşlarak hesaplanan }
\end{tabular}
eğitim turizmi rekabet avantajında Amerika'nın rekabet gücü üstünlüğü dikkat çekmektedir (2016 RCA 3,39). Gerek Türkiye (2016 RCA 0,09), gerek Tayland (RCA 2015 0,01) eğitim turizminde rekabet üstünlüğü yakalayamamış ülkelerdir. Hatta eğitim adına pek fazla turisti (yabancı uyruklu öğrenciyi) ülkelerine çekememektedirler. Amerika'nın gelişmiş ve 


\section{Nurdan KUŞAT}

gelişmeye devam eden teknolojisi, yabancı öğrenciler için bu ülkeyi popüler hale getiren en önemli unsur olmaktadır.

Tablo 14. Diğer Turizm Türleri RCA Endeksi Değerleri

\begin{tabular}{llll} 
Yıllar & Türkiye & Amerika & Tayland \\
\hline 2012 & 1,24 & - & 1,40 \\
2013 & - & 0,85 & 1,37 \\
2014 & - & 0,85 & 1,36 \\
2015 & 1,08 & 0,84 & 1,32 \\
2016 & 1,08 & 0,81 & - \\
\hline
\end{tabular}

Sağık ve eğitim dışında kalan diğer turizm faaliyetlerinde ise Türkiye ve Tayland'ın rekabet avantajı yakalayan ülkeler olduğu görülmektedir (her iki ülkede de RCA değerleri incelenen her yıl için 1'in üzerinde hesaplanmıştır). Sağlık ve eğitim dışında kalan ve turistik arzı oluşturan diğer faktörler düşünüldüğünde (coğrafya, iklim, kültür vb.) bu sonuçların elde edilmiş olması çok da şaşırtıcı değildir. Amerika ise bu faaliyet alanında rekabet avantajı yakalayamamaktadır.

\section{CEP - Karşılaştırmalı İhracat Performansı Endeksi Sonuçları}

Türkiye ve dünya toplam turizm gelirinden en yüksek payı alan 5 ülkenin turizm sektöründeki karşılaştırmalı inracat performansları CEP endeksi yardımıyla hesaplanmıştır. Bu hesaplamada ülkelerin toplam hizmet ticareti ve bu hizmet ticareti içerisinde yer alan turizm faaliyetine ait değerler kullanılmıştır. (200 ve 236 kodlu değerler kullanılarak hesaplama yapılmıştır). Elde edilen sonuçlar Tablo $15^{\prime}$ de verilmektedir.

Tablo 15: Türkiye'nin Turizm Sektöründe 5 Ülke Karşısındaki Karşılaştırmalı İhracat Performansı (CEP)

\begin{tabular}{llllll} 
& Türkiye / & $\begin{array}{l}\text { Türkiye / } \\
\text { İspanya }\end{array}$ & $\begin{array}{l}\text { Türkiye / } \\
\text { Tayland }\end{array}$ & $\begin{array}{l}\text { Türkiye / } \\
\text { Çin }\end{array}$ & $\begin{array}{l}\text { Türkiye / } \\
\text { Fransa }\end{array}$ \\
\hline 2012 & 2,32 & 1,23 & 0,86 & 2,24 & 2,36 \\
2013 & 2,24 & 1,18 & 0,82 & 2,07 & 2,42 \\
2014 & 2,15 & 1,17 & 0,82 & 2,11 & 2,48 \\
2015 & 2,02 & 1,20 & 0,78 & 1,31 & 2,81 \\
2016 & 1,77 & 1,04 & 0,35 & 2,08 & 2,55 \\
\hline
\end{tabular}

Türkiye turizm sektörü, örneklemde yer alan ülkelerden Tayland haricinde hepsi karşısında yüksek bir ihracat performansı göstermektedir. Turizm sektörü ihracat değerlerinin tamamı gözetilerek yapılan bu hesaplamada Türkiye en büyük ihracat performansını Fransa karşısında göstermekte (2016 CEP değeri 2,55), bu üstünlüğünü sırasıyla Çin (2016 CEP değeri 2,08), Amerika (2016 CEP değeri 1,77) ve İspanya (2016 CEP değeri 1,08$)$ karşısında tekrarlamaktadır. Tayland karşısında ise herhangi 
bir ihracat performansı yakalayamadığı gözlenmektedir (2016 CEP değeri $0,35)$. Bu sonuçlar Türkiye'nin Turizm sektörü genelindeki en güçlü rakibinin (örneklem dahilinde) Tayland olduğunu göstermektedir.

Örnekleme dahil edilen ülkelerde kişisel amaçla gerçekleştirilen turistik faaliyetlerin sağlık, eğitim ve diğer alt başıklardaki karşılaştırmalı ihracat performanslarının ölçümlemesi yapılarak; Tablo 16, 17 ve 18'de hesaplama sonuçları verilmiştir. Fakat bu hesaplamalar için her ülkenin ayrıntılı verilerine ulaşılamadığından, sadece ulaşılabilen veriler kullanılmış ve bazı ülkeler ve yıllar için hesaplama yapılamamıştır.

Tablo 16: Türkiye'nin Sağlık Turizminde Karşılaştırmalı İhracat Performansı (CEP)

\begin{tabular}{lllll} 
Ylllar & Türkiye / Amerika & & \\
\hline 2012 & - & & & \\
2013 & - & & & \\
2014 & - & & & \\
2015 & 1,73 & & & \\
2016 & 1,69 & & & \\
\hline Ulaşılabilen & verilerle & gerçekleştirilen & sağlık turizmi & CEP
\end{tabular}

ölçümlemesine göre, Türkiye'nin Amerika karşısında yüksek bir ihracat performansı yakalamış olduğu söylenebilir (2016 CEP değeri 1,69). Bu sonuç Türkiye'nin sağlık turizmindeki cazibesini, aynen RCA değerlerinin de gösterdiği gibi, teyit eder niteliktedir.

Tablo 17: Türkiye'nin Eğitim Turizminde Karşılaştırmalı İhracat Performansı (CEP)

\begin{tabular}{lll} 
YIllar & Türkiye / Amerika & Türkiye /Tayland \\
\hline 2012 & 0,05 & 1,75 \\
2013 & & \\
2014 & & \\
2015 & 0,05 & 2,88 \\
2016 & 0,05 & \\
\hline
\end{tabular}

Veri eksikliği nedeniyle; eğitim turizmi adına Türkiye'nin sadece Amerika ve Tayland'la karşılaştırmalı ihracat performansı hesaplanabilmiştir. Bu hesaplama sonuçları eğitim turizminde Türkiye'nin Amerika karşısındaki düşük performansını (2016 CEP 0,05), Tayland karşısındaki yüksek performansını $(2015$ CEP 2,88) ortaya koymaktadır. $\mathrm{Bu}$ durum Türkiye'nin yabancı öğrencileri ülkeye çekme kabiliyetinin Amerika'yla kıyaslanamayacak kadar zayıf, ama Tayland'la kıyaslandığında güçlü olduğunu göstermektedir. 


\section{Nurdan KUŞAT}

Tablo 18: Türkiye'nin Diğer Turizm Faaliyetlerinde Karşılaştırmalı İhracat Performansı (CEP)

\begin{tabular}{lll} 
Ylllar & Türkiye /Amerika & Türkiye /Tayland \\
\hline 2012 & - & 0,99 \\
2013 & - & - \\
2014 & - & - \\
2015 & 0,69 & 0,96 \\
2016 & 0,77 & - \\
\hline
\end{tabular}

Veri eksikliği nedeniyle; sağlık ve eğitim dışında kalan diğer turistik faaliyetlerde Türkiye'nin sadece Amerika ve Tayland'la karşılaştırmalı ihracat performansı hesaplanabilmiştir. Bu hesaplama sonuçları Türkiye'nin Amerika ve Tayland karşısında diğer turistik faaliyetlerdeki ihracat performansı düşüklüğünü göstermektedir (2016 Türkiye/Amerika CEP 0,77, 2015 Türkiye/Tayland CEP 0,96). Bu sonuçlar dünya turizm gelirinden büyük paylar alan Amerika ve Tayland'ın, eğitim ve sağlık turizmi dışında kalan alanlarda da Türkiye karşısında güçlü birer rakip olduğunun birer göstergesi olarak kabul edilebilir.

\section{SONUÇ VE ÖNERİLER}

Yeni ekonomik düzen, dünya ekonomileri arasındaki rekabetin şiddetini artırırken, gelişmiş ülkeler mevcut pastadaki paylarını kaybetmemek hatta artırmak, gelişmekte olan ülkeler de bu pastadan daha büyük paylar elde etmek amacıyla çabalarını sürdürmektedir. Aslında bu süreç ülkelerin mevcut mal ve hizmet sektörlerindeki rekabet güçlerini artırma çabaları olarak da değerlendirilebilir.

Gelişmiş ülkeler için rekabet gücünü artırmak, zaten var olan yüksek sermaye birikimleri ve üstün teknolojik yapılarıyla çok zor olmasa da; bu imkanlara kısıtlı ölçüde sahip olan gelişmekte olan ülkeler için önemli bir sorun teşkil etmektedir. Bu açıdan gelişmekte olan ülkeler için kurtarıcı bir sektöre intiyaç duyulur ki bu sektör genelde 'turizm sektörü' olarak kendisini gösterir.

Turizm sektörünün ekonomiler için popüler hale gelmesi büyük ölçüde; mevcut turistik arzın düşük maliyetlerle yüksek döviz geliri yaratarak ödemeler dengesi açıklarının kapatılmasına pozitif katkı sağlayabilme potansiyelinden kaynaklanmaktadır. Sektörün çok fazla ithal girdiye gereksinim duymaması, sektörde yabancı sermaye yerine öz sermaye kullanımının yoğunluğu bu sürecin tetikleyicisi olmaktadır. Ayrıca turizmin ülke istihdamına pozitif etkileri, kırdan kente göçü yavaşlatan yapısı ve dikey ve yatay periyotta diğer sektörleri tetikleyici gücü bu 
sektörü son yüzyılın muhtemel en popüler sektörü statüsüne kavuşturmaktadır. Dünya refah düzeyindeki ve dünya vatandaşlarının seyahat eğilimlerindeki artışlar da sektörü ekonomik kalkınmanın lokomotif sektörü olma düzeyine sevk eden bir yapılanma oluşturmaktadır.

Çalışma Türk turizm sektörünün hem rekabet gücünü, hem de dünya turizm gelirleri pastasından en büyük payı alan 5 ülke karşısındaki karşılaştırmalı üstünlüğünü ölçmek amacıyla gerçekleştirilmiştir. Bu amaç doğrultusunda da, literatürde yaygın olarak kullanılan RCA ve CEP endekslerinden yararlanılmıştır.

Çalışma bulguları, örnekleme dahil edilen ülkeler arasında Türkiye'nin en güçlü rakibinin Tayland olduğu sonucunu ortaya koymaktadır. Her ne kadar Türkiye dışında örnekleme dahil edilen ülkeler dünya genelinde en yüksek turizm geliri elde eden ülkeler olsalar da, gerek RCA, gerek CEP endeks değerleri bu sonuca varılmasına önderlik etmektedir.

RCA sonuçlarına göre Çin hariç; Türkiye ve diğer ülkelerin (ABD, İspanya, Tayland, Fransa) dünya turizm sektöründe rekabet avantajına sahip ülkeler olduğu gözlenmektedir. En yüksek rekabet gücüne sahip ülke ise Tayland olup, Türkiye hemen Tayland'ın arkasında yerini almaktadır (Tablo 9).

Türkiye baz alınarak hesaplanan CEP sonuçlarına göre de, Türkiye'nin sadece Tayland karşısında düşük inracat performansı gösterdiği, diğer ülkeler karşısında ise iyi bir ihracat performansı elde ettiği görülmektedir (Tablo 15).

Turizm sektörünün bir bütün olarak ele alınmasıyla gerçekleştirilen RCA ve CEP endeksleri hesaplama sonuçları, her Türk vatandaşının az ya da çok bildiği bir gerçeği bilimsel olarak teyit eder özelliktedir: 'Türkiye, dünya turizm sektöründe rekabet gücü yüksek olan bir ülkedir.'

OECD ve EUROSTAT'ın ortak sınıflandırma sistemi EBOPS'a göre turistik faaliyetler, iş ve kişisel amaçla gerçekleştirilen turistik faaliyetler olarak sınıflandırımaktadır. RCA endeksi hesaplama sonuçları Türkiye'nin iş amaçlı gerçekleştirilen turistik faaliyetlerde bir rekabet avantajı yakalayamamasına karşın (Tablo 10), iş amaçlı gerçekleştirilen faaliyetlerde belirli bir avantaj yakaladığını (Tablo 11) göstermektedir. Ayrıca Türkiye'nin iş amaçlı gerçekleştirilen turistik faaliyetlerdeki en önemli rakipleri Amerika ve Tayland olurken, kişisel amaçlı faaliyetlerdeki en güçlü rakibi Fransa olarak bulunmuştur. 


\section{Nurdan KUŞAT}

EBOPS sınıflandırma sistemine göre kişisel amaçlı turistik faaliyetler; eğitim, sağlık ve diğer faaliyetler olarak ayrıca bölümlenmektedir. Gerçekleştirilen RCA hesaplamaları sağlık turizminde Türkiye'nin (Tablo 12), eğitim turizminde Amerika'nın (Tablo 13) ve diğer turizm faaliyetlerinde Tayland'ın rekabet üstünlüklerini ortaya çıkarmaktadır (Tablo 14). Bu sonuçları çalışmada hesaplanan CEP sonuçları da teyit etmekte olup; Türkiye'nin Amerika karşısında sağık turizminde (Tablo 16), Tayland karşısında eğitim turizminde yüksek ihracat performansını doğrulamaktadır (Tablo 17). Aynı zamanda CEP sonuçları Türkiye'nin eğitim turizmindeki ihracat performansı düşüklüğünü ve Amerika ve Tayland karşısındaki diğer turistik faaliyetlerdeki yetersizliğini de göstermektedir (Tablo 18).

Elde edilen bulgular çerçevesinde Türkiye turizm sektörünün rekabet gücünü genel olarak değerlendirmek mümkündür. Türkiye turizm sektörü her ne kadar dünya turizm gelirleri toplamından yeterli pay alamıyor olsa da, yüksek rekabet avantajına sahip bir sektördür. Aynı zamanda bu sektördeki ihracat performansı da oldukça yüksektir. Rekabet avantajı yakaladığı turistik faaliyetlerin başında da kısmi olarak eğitim dışında kalan; sağlık turizmi ve diğer turizm faaliyetleri gelmektedir.

Türkiye bir sanayi ülkesi değildir. Türkiye ekonomisinin sürükleyicisi hizmet sektörüdür. Türkiye'nin hizmet sektöründe de en önemli ivmeyi turizm sektöründen elde ettiği aşikardır. Bu açıklamalar birer iddia ya da birer sav değildir. Günümüzde Türkiye Cari İşlemler Dengesi sürekli açık vermekte, hata bu açıklar gittikçe artmaktadır. Bu açıkları bir ölçüde telafi etmekte olan Hizmetler Dengesi'nin en önemli alt kalemi ise, Turizm sektörüdür. T.C. Merkez Bankası resmi internet sitesinde paylaşılan istatistikler; Türkiye'nin 2017 yılı cari işlem açıklarının 47.436 milyon \$ olarak açıklamakta, hizmet dengesi içerisinde yer alan seyahat kaleminin bu açıklara pozitif yönlü katkısının 22.478 milyon\$ olduğunu göstermektedir (www.tcmb.gov.tr). Ayrıca aynı site hizmetler dengesinin cari işlem açıklarına olan katkısının, yine pozitif ve 2017 yılı için 19.940 milyon \$ olduğunu paylaşmaktadır.

Bu açıdan turizm sektörüne ve sektörün rekabet gücünü daha da yukarıya taşıma adına yapılabilecek en anlamlı uygulamaların; turizme destek olan ve turizmle iç içe geçmiş olan hizmet sektörlerinin rekabet gücünü artırmak olduğu düşünülebilir. Konaklama işletmelerinden seyahat acentalarına, sağlık işletmelerinden bankalara, sigorta şirketlerinden lokanta ve restoranlara kadar pek çok hizmet alanı bu konunun kapsamına girer. Öncelikle Kültür ve Turizm Bakanlığı'nın önderliğinde 
hazırlanacak ve sonrasında turizme dolaylı ya da doğrudan katkı veren bakanlıkların da görüş ve önerilerine açılacak uzun soluklu politik düzenlemelere intiyaç vardır. Bu düzenlemelerin şekillenmesi için de sektörle ilgisi olan üniversite hocaları ve sivil toplum kuruluşlarının desteği sağlanmalıdır. Bu düzenlemeler sadece günü kurtarmaya yönelik gelip geçici politikalar değil, sürdürülebilirliği yüksek kalıcı uygulamalar olarak kurgulanmalıdır.

Fakat çalışma sonuçlarının daha anlamlı hale gelebilmesi ve sonuçların daha doğru değerlendirilebilmesi için; turizm sektörüne yatay ve dikey ölçekte kaynak sağlayan tüm sektörlerin rekabet avantajlarının da benzer çalışmalarla ölçülmesine intiyaç duyulmaktadır. Çalışma diğer sektörlere yönelik çalışmalarla desteklendiği ölçüde anlamlıık düzeyini artıracaktır.

\section{KAYNAKÇA}

Akgüngör, S., Barbaros, R. F. ve Kumral, N. (2002). Competitiveness of the Turkish Fruit and Vegetable Processing Industry in the European Union Market. Russian \& East European Finance and Trade, 38(3), 34-53.

Alidou, M., Ceylan, R. F. ve Ilbasmıs, E. (2017). Trade and Revealed Comparative Advantage Measures: A Case of Main Export Crops of Benin Republic. Kastamonu Üniversitesi İktisadi ve İdari Bilimler Fakültesi Dergisi, 18(1): 382-397. ICEBSS 2017 Özel Sayı.

Altay, N.O. ve Gacaner, A. (2003). Turkey's Dynamics of Competition: A Comparative Analysis of Competitiveness of The Textile and Clothing Industry. Paper Presented at the VII. ERC/METU International Economy Congress, Ankara.

Amighini, A., Leone, M. ve Rabellotti, R. (2011). Persistence Versus Change in the International Specialization Pattern of Italy: How Much Does the 'District Effect' Matter?. Regional Studies, 45(3): 381-401.

Balassa, B. (1965). Trade Liberalization and 'Revealed' Comparative Advantage. The Manchaster School of Economic and Social Studies, 33 (2): 99-123.

Barattieri, A. (2014). Comparative Advantage, Service Trade, and Global Imbalances. Journal of International Economics. 92:1-13.

Bilas, V. ve Bošnjak, M. (2015). Revealed Comparative Advantage and Merchandise Exports: The Case Of Merchandise Trade Between 


\section{Nurdan KUŞAT}

Croatia and The Rest of the European Union Member Countries. Ekon., Misao Praksa Dbk. God XXIV., Br. 1. 29-47.

Coxhead, I. (2007). A New Resource Curse? Impacts of China's Boom on Comparative Advantage and Resource Dependence in Southeast Asia. World Development, 35(7):1099-1119.

Çoban, O. ve Kök, R. (2005). Türkiye Tekstil Endüstrisi ve Rekabet Gücü: AB Ülkeleriyle Karşılaştırmalı Bir Analiz Örneği (1989-2001). İktisat, İşletme ve Finans Dergisi, 20(228): 68-81.

De Benedictis, L. ve Tamberi, M. (2002). A Note on the Balassa Index of Revealed Comparative Advantage. Universita' Politecnica delle Marche (I). Dipartimento di Scienze Economiche e Sociali. Working Papers 158.

Donges, J.B., Krieger-Boden, C., Langhammer, R. J., Schatz, K.W. ve Thoroe, C.S. (1982). The Second Enlargement of the European Community: Adjustment Requirements and Challenges for Policy Reform. Kieler Studien. N.171. Kiel.

Edinsel, S. ve Adıgüzel, O. (2014). Türkiye'nin Sağılı Turizmi Açısından Son Beş Yıldaki Dünya Ülkeleri İçindeki Konumu ve Gelişmeleri. Çankırı Karatekin Üniversitesi, İktisadi ve İdari Bilimler Fakültesi Dergisi, 4(2): 167-190.

Erlat, G. ve Erlat, H. (2012). Türkiye'nin Orta Doğu Ülkeleri ile Olan Ticareti - 1990-2002. Editörler: Uygur, E. ve Civcir, İ. GAP Bölgesinde Dış Ticaret ve Tarım (2004). TEK Yayını.

Ferto, I. ve Hubbard, L. (2002). Revealed Comparative Advantage and Competitiveness in Hungarian Agri-Food Sectors Technology Foresight in Hungary. Institute of Economics Hungarian Academy of Sciences. Discussion Papers, 2002/8.

Gacaner Atış, A. (2014). Türkiye'nin Tekstil ve Konfeksiyon Sektörünün Karşılaştırmalı Rekabet Analizi. Ege Akademik Bakış, 14(2): 315334.

Hatırlı, S.A., Demircan, V. ve Özkan, B. (2003). Tekstil ve Konfeksiyon İhracatında Türkiye'nin Rekabet Durumu. Türkiye VI. Pamuk, Tekstil ve Konfeksiyon Sempozyumu Bildirileri. Tarımsal Ekonomi Araştırma Enstitüsü, N.106:115-122.

Hinloopen, J. ve Van Marrewijk, C. (2001). On the Empirical Distribution of the Balassa Index. Review of World Economics, 137(1):1-35

Hossain, M.B. (2006) Export Performance of Bangladesh's Fisheries Sector. The Journal of Developing Areas, 39(2):36-77, Spring 2006. 
Jayawickrama, A. ve Thangavelu, S.M. (2010). Trade Linkages between China, India and Singapore: Changing Comparative Advantage of Industrial Products. Journal of Economic Studies, 37(3):248-266.

Kaitila, V. ve Wigren, M. (1999). Revealed Comparative Advantage in Trade between the European Union and the Baltic Countries. The Research Institute of the Finnish Economy Discussion Papers, No. 697.

Kara, O. ve Erkan, B. (2011). Türkiye'nin Emek Yoğun Mal İhracatındaki Karşılaştırmalı Üstünlüklerin Makroekonomik Büyüklüklerle İlişkisi. Ekonomik ve Sosyal Araştırmalar Dergisi, Bahar, 7(1):67-93.

Kösekahyaoğlu, L. (2012). Diş Ticaret ve Rekabet Gücü: 1923-2011, Alter Yay. Rek. Org. Tic. Ltd. Şti., Ankara.

Kösekahyaoğlu, L. ve Özdamar, G. (2005). Türkiye, Çek Cumhuriyeti, Macaristan, Polonya ve Estonya'nın Sektörel Rekabet Gücü ve Dış Ticaret Yapısı Üzerine Karşılaştırmalı Bir Analiz. Sosyoekonomi, Temmuz-Aralık, 2:73-102.

Lin, J. Y., Cai, F. ve Li, Z. (1996). The China Miracle: Development Strategy and Economic Reform. Hong Kong: Chinese University Press.

Mahajan, V., Nauriyaland, D.K. ve Singh SP. (2015). Trade Performance and Revealed Comparative Advantage of Indian Pharmaceutical Industry in New IPR Regime. International Journal of Pharmaceutical and Healthcare Marketing, 9(1):56-73.

Riaz, K. ve Jansen, H.G.P. (2012). Spatial Patterns of Revealed Comparative Advantage of Pakistan's Agricultural Exports. Pakistan Economic and Social Review, 50(2):97, Winter 2012.

Saraçoğlu, B. ve Köse, N. (2000). Bazı Gıda Sanayilerinin Uluslararası Rekabet Gücü: Makarna, Bisküvi ve Un Sanayi, Proje Raporu 20002, Mayıs 2000, Ankara.

Serin, V. ve Civan, A. (2008). Revealed Comparative Advantage and Competitiveness: A Case Study for Turkey Towards the EU. Journal of Economic and Social Research, 10(2): 25-41.

Seyoum, B. (2007). Revealed Comparative Advantage and Competitiveness in Services: A Study with Special Emphasis on Developing Countries. Journal of Economic Studies, 34(5): 376 388.

Şahin, D. (2016). İmalat Sanayinde Rekabet Gücünün Ölçümü: Türkiye ve BRIC Ülkeleri Örneği. Ege Akademik Bakış, 16(4):709-718, Ekim 2016. 


\section{Nurdan KUŞAT}

Türkekul, B., Günden, C., Abay, C. ve Miran, B. (2010). The Competitiveness of Turkish Olive Oil on the World Market. Journal of Food, Agriculture and Environment, 8(2), 68-73.

Türkiye Cumhuriyeti Merkez Bankası. http://www.tcmb.gov.tr/wps/wcm/connect/TR/TCMB+TR/Main+M enu/Istatistikler/Odemeler+Dengesi+ve+Ilgili+Istatistikler/Odemel er+Dengesi+Istatistikleri/ (27.09.2018)

Türkiye'de Sürdürülebilir Kalkınma Raporu: Geleceği Sahiplenmek, Kalkınma Bakanlığı. (2012). Ankara. (http://www.surdurulebilirkalkinma.gov.tr/wpcontent/uploads/2016/07/1.Gelecegi_Sahiplenmek.pdf) (27.09.2018)

Türkiye İstatistik Kurumu (TUİK). http://www.tuik.gov.tr/UstMenu.do?metod=istendeks (01.07.2018)

United Nations. Departmant of Economic and Social Affairs. Statistics Division. Trade Statistics. https://comtrade.un.org/data/ (15.07.2018)

Utkulu, U. ve Seymen, D. (2004). Revealed Comparative Advantage and Competitiveness: Evidence for Turkey vis-a-vis the EU/15. Paper Presented on the European Trade Study Group 6th Annual Conference ETSG, Nottingham.

World Tourism Organization UNWTO Tourism Highlihts: 2017 Edition. https://www.e-unwto.org/doi/book/10.18111/9789284419029 (01.07.2018)

World Trade Organisation (WTO) https://www.wto.org (27.09.2018)

Yeşilkaya, M. (2017). "Sürdürülebilir Kalkınmada Dış Ticaretin Yeri ve Önemi: Türkiye ve BRIC Ülkelerinin Karşılaştırmalı Analizi", Vol:3, Issue:13; pp:67-84 (ISSN:2149-8598)

Yücel, Y. (2010). Uluslararası Ticaretin Serbestleştirilmesi Sürecinde Türk Tekstil ve Hazır Giyim Sektörünün Rekabet Gücü ve Çin Tehdidi. Marmara Üniversitesi İ.İ.B.F. 